Article

\title{
Analysis of Musculoskeletal Disorders and Muscle Stresses on Construction Workers' Awkward Postures Using Simulation
}

\author{
Shraddha Palikhe ${ }^{1}$, , Mi Yirong ${ }^{2}$, Byoung Yoon Choi ${ }^{2}$ and Dong-Eun Lee ${ }^{2, *(\mathbb{D}}$ \\ 1 Intelligent Construction Automation Center, Kyungpook National University, Daegu 41566, Korea; \\ arpsharu@gmail.com \\ 2 School of Architecture, Civil, Environment, and Energy Engineering, Kyungpook National University, \\ Daegu 41566, Korea; miyirong@knu.ac.kr (M.Y.); jr1381@knu.ac.kr (B.Y.C.) \\ * Correspondence: dolee@knu.ac.kr; Tel.: +82-53-950-7540
}

Received: 15 May 2020; Accepted: 8 July 2020; Published: 15 July 2020

\begin{abstract}
The negligence involved in musculoskeletal disorder (MSD) at construction sites results in high rates of muscle injuries. This paper presents findings identified by the MSD for each part of a worker's body, categorizing the awkward postures of each body part, estimating muscle stresses, and establishing the benchmark using anthropometry and hand force data. MSDs and their corresponding frequencies were identified by administering the Nordic Musculoskeletal Questionnaire (NMQ) survey, which solicits responses regarding construction workers' awkward postures. Musculoskeletal stresses were estimated using three-dimensional static strength prediction program (3D SSPP) biomechanical software. The new benchmarks were established for existing preventive measures using the anthropometry and hand force data. Workers suffering from different body muscle pains in awkward postures may be predicted using the compression forces magnitude, strength capability, and body balance. The model was verified by comparing its outputs with the survey analysis results. The study is of value to practitioners because it provided a means to understand the contemporary scenario of MSD and to establish a practical benchmark based on the physical capability of workers. It is relevant to researchers because it digitally predicts MSD and facilitates experimentation with different dimensions, thereby contributing to construction productivity improvement. Test cases validate the prediction method.
\end{abstract}

Keywords: musculoskeletal disorders; construction workers; muscle stress; standard Nordic questionnaire; awkward posture; simulation

\section{Introduction}

Construction is ranked as the most hazardous operation involving musculoskeletal disorders and injuries. MSDs are caused by sudden exertion or prolonged exposure to physical factors (i.e., high force, repetitive motion, awkward body posture, and vibration) and affects the muscles, nerves, tendons, joints, cartilage, and supporting structures of the upper and lower limbs, neck, and lower back, etc. [1]. MSDs are attributed to handling heavy manual materials, manipulating excessive and repetitive hand tools, performing repetitive screw motions, reinforcing works involving difficult postures, and so on [2]. When the working posture differs from the neutral posture in which the body is aligned and balanced while placing minimal stress on the muscles, tendons, nerves, and bones, the stress on the body parts (i.e., the muscles, tendons, joints, arms, hands, and shoulders) increases, resulting in awkward postures and/or movements of the body parts of the workers, in turn leading to a negative impact on the safety and health of the workers as well as on productivity. The percentage of construction workers exposed 
to the musculoskeletal hazards in Korea while carrying heavy loads, standing long, and maintaining tiring and painful positions, is about $72 \%, 83.8 \%$, and $67.9 \%$, respectively [3]. Herein, we identify the factors that either affect ergonomic interventions or reduce MSDs in construction workers (i.e., masons, pavers, and electricians) [4].

Existing studies provide ergonomic analysis methods that employ motion sensing and assessment tools [5] to alleviate MSDs or to implement preventive measures. However, the correlation between anthropometry and the magnitude of hand forces has not been well explored. A new ergonomic analysis method that identifies the correlation between these two will be beneficial to a construction administrator for estimating, say, the compression on the lower back, and for establishing a benchmark of the workload imposed on a worker using BMI and hand forces exerted in diverse working postures (i.e., pushing forward, lifting, stooping, and kneeling). Such estimations may contribute to securing labor safety and health by efficiently identifying competent workers from an ergonomic viewpoint for the given work task. Three dimensions of environment, society, and economy are frequently used to model how sustainability can be incorporated into one's mission, goals, and practices. However, the issues involved in the social dimension of sustainability (i.e., labor relations, diversity, workers benefits/compensation, human rights, the organization of work, etc.) have often been overlooked, resulting in negative impacts (i.e., hazards to workers and creating tension between goals). Many worker issues exist within the concept of sustainability. The proposed posture simulation and benchmarking approach, relevant to the workers' social issues that promotes labor welfare, safety, and health.

The research was conducted in five steps. First, the performance of existing ergonomic modeling and analysis methods for the construction industry was investigated through a literature review to identify new research contributions. Second, a set of Nordic Musculoskeletal Questionnaire surveys was administered to workers from various construction trades to identify the MSD issues of each trade. The ergonomic data, including the MSDs affecting various body parts of workers, were collected from workers engaged in bare-hand manual operations in four Korean construction sites. Third, the new ergonomic model that establishes a benchmark of the workload imposed on construction workers engaged in diverse working postures was implemented in an automated tool by mapping the survey findings into a three-dimensional static strength prediction program (3D SSPP) software. Fourth, the model performance was demonstrated using a set of working postures (i.e., pushing forward, lifting, stooping, and kneeling). The validity and effectiveness of the model were verified by performing a series of case studies, each of which the common awkward body postures were identified and the static strength and compressive forces attributed to each awkward posture were estimated using 3D SSPP. It was confirmed that the model established the benchmark using hand force and body mass index (BMI). Finally, the research contributions and limitations were examined. The material in this paper is organized in the same order. Indeed, the findings will be of help for construction administrators to understand MSD issues experienced by workers employed in a specific operation and will provide clues to identify those tasks that can be semi-automated or fully-automated for better benefits.

\section{Current State of Musculoskeletal Disorder Studies}

MSD is the highest contributor to global disability, accounting for $16 \%$ of all years lived with disability; lower back pain is the single leading cause (Global burden of disease, 2017). In South Korea, the percentage of workers aged 50 years or older was $25 \%$ in 2010 and this value is expected to exceed 33\% in 2020 [6]. Workers suffering from MSDs include aged construction craftsmen exposed to severe vibrations, construction and mining technicians, and construction finishing workers (61.3\%, 47.8\%, and 46\%, respectively). The prevalence of chronic MSDs and degradation of body parts attributed to aging may lead to decreased physical labor capability. The frequency of back pain, upper extremities, and lower extremities and fatigue are chronically high in construction workers, about $30.7 \%, 61.3 \%, 49.2 \%$, and $35.6 \%$, respectively [3]. Existing studies claim that, compared to young workers, aged workers are more likely to suffer from musculoskeletal symptoms. 
Meanwhile, existing ergonomics analysis techniques may be classified into self-reporting, manual observation, direct sensing measurement, and vision-based analysis. Self-reporting is a data collection process that involves conducting interviews and web-based questionnaires [7]. Manual observation tools facilitate measuring and/or evaluating MSD via hybridizing body position and movement-tracking tools (e.g., assessment of repetitive task, Ovako working posture analysis system, posture activity tools and handling, rapid upper limb assessment, and rapid entire body assessment (REBA)) [8]. However, they lend themselves neither to a precise posture measurement nor to the recording of delicate movement patterns such as that possible in time-lapse video observation. In direct sensing measurement, various sensor(s) are attached to the body parts of workers; these approaches outperform the two approaches in terms of measurement accuracy. The accuracy may be augmented by hybridizing the measurement method with Microsoft Kinect Cameras for efficient real-time motion analysis $[9,10]$. Vision-based analysis allows for precise motion tracking along with biomechanical parameter measurements that use devices such as tapes and goniometers, microelectromechanical systems (MEMS), electrodes for electromyography (EMG), and magnetoresistive sensors. Although this method facilitates measuring joint angles, including the angle of the neck, it is cumbersome because construction workers must wear devices while working. Although it outperforms existing methods, methods based on such analysis are still far from the ideal [11].

Existing studies have identified that construction workers suffer from physical fatigue and muscle pain when exposed to excessive energy consumption, resulting in human error, unsafe actions, and productivity loss, etc. In addition, a few studies claim that practical methods that assess MSD risks to all parts of the body are necessary in construction, proposing new technologies that facilitate the identification of preventive measures involved in appropriate body posture [12]. However, they are not yet arrived in a maturity to proper implementation. MSD remains a substantial concern with considerable personal and societal burdens [13]. Indeed, it would be beneficial to enlighten MSD issues to the construction practitioners hybridizing posture simulation and survey methods. It may contribute to identifying human MSD along with a benchmarking approach that supports making preventive MSD tools for construction personnel.

For construction workers, the anthropometric traits and hand forces to which different body parts (i.e., the neck, shoulder, fingers, knee, and wrist) are subjected depend on the task types (i.e., overhead work, ground-floor-level work, and manual material-handling work) [14]. Several musculoskeletal injury prevention measures (e.g., site-specific ergonomics programs, engineering controls, mechanical devices, exercise programs) have been enforced to reduce the burden of manual-lifting hazards. The "best practices" do not cause pain and/or discomfort in the back and wrist, and were identified to increase the productivity [2,15]. These measures encourage the development of initiatives that analyze ergonomic hazards and implement site-specific mitigation strategies and practices. It will be beneficial to reengineer improvement techniques and to upgrade its dynamic condition against work-related MSDs. Existing studies provide methods to identify the body postures of workers and suggest their corresponding preventive measures. However, these studies did not deal with tracking transitory motion changes at an appropriate level of detail or modeling MSDs in a working environment. Therefore, construction safety still incurs considerable personal and socioeconomic burden. A new simulation modeling, analysis, and controlling tool that effectively handles the MSD issues faced by workers involved in a construction operation will be beneficial. A simulation model formulated based on worker survey results may contribute to the construction safety and health by establishing a benchmark for actioning MSD-prevention measures.

\section{Materials and Methods}

\subsection{Research Method}

The research method map is shown in Figure 1. Each stage of this research consisted of four "processes" with two "outputs," indicated by numbers (1) to (5). For each "process," a set of criteria 
(or standard mean) were used to identify the variables and develop a simulation model. First, the variables involved in the MSDs of workers (i.e., anthropometry and hand forces) were identified through comprehensive literature reviews. Second, comprehensive literature reviews were conducted to identify the variables involved in the MSDs of workers (i.e., anthropometry and hand forces). Third, the variables that influenced the MSD symptoms of workers were confirmed by surveying workers actively engaged in construction tasks. Anthropometry and hand force data for awkward postures were obtained from the NMQ survey. The outputs show that three motions (i.e., pushing forward, lifting, and kneeling) among the awkward postures manifested on a specific task deserve special attention. The justification for using these variables for MSDs was confirmed via a survey. Third, the data of these variables were used as the input parameters for simulation using 3D SSPP (Ver. 2017), an easy-to-use model that considers all variables together. This model estimates physical demands by considering input postures in a specified window frame, predicting the changes physical demands as the workers shift from one posture to another, capturing and saving pictures of each awkward posture, creating a digital twin of virtual workers using the photos, duplicating postures, and calculating the lower back compression and body balance. In addition, the anthropometric data, hand load measured for each construction task, and loads obtained from workers' experience, were mapped into the modeled virtual workers. The validity of the survey output was confirmed by comparing it with the simulation output data from a series of simulation experiments. The preventive measures to reduce MSDs were discussed using the obtained static strength for postures. Body balance was assessed by computing the center-of-pressure (COP) and evaluating the location of the COP projected onto the floor while taking into account the limits of the functional stability region using 3D SSPP. Fifth, the benchmark was established according to BMI and corresponding hand forces by changing the magnitude of the hand forces while keeping the body weight constant. In addition, the model was tested under several different sets of variables to estimate lower back compression, percentage of accurate predictions, and body balance. Finally, the contributions and limitations of the model and suggestions for its improvement were discussed.

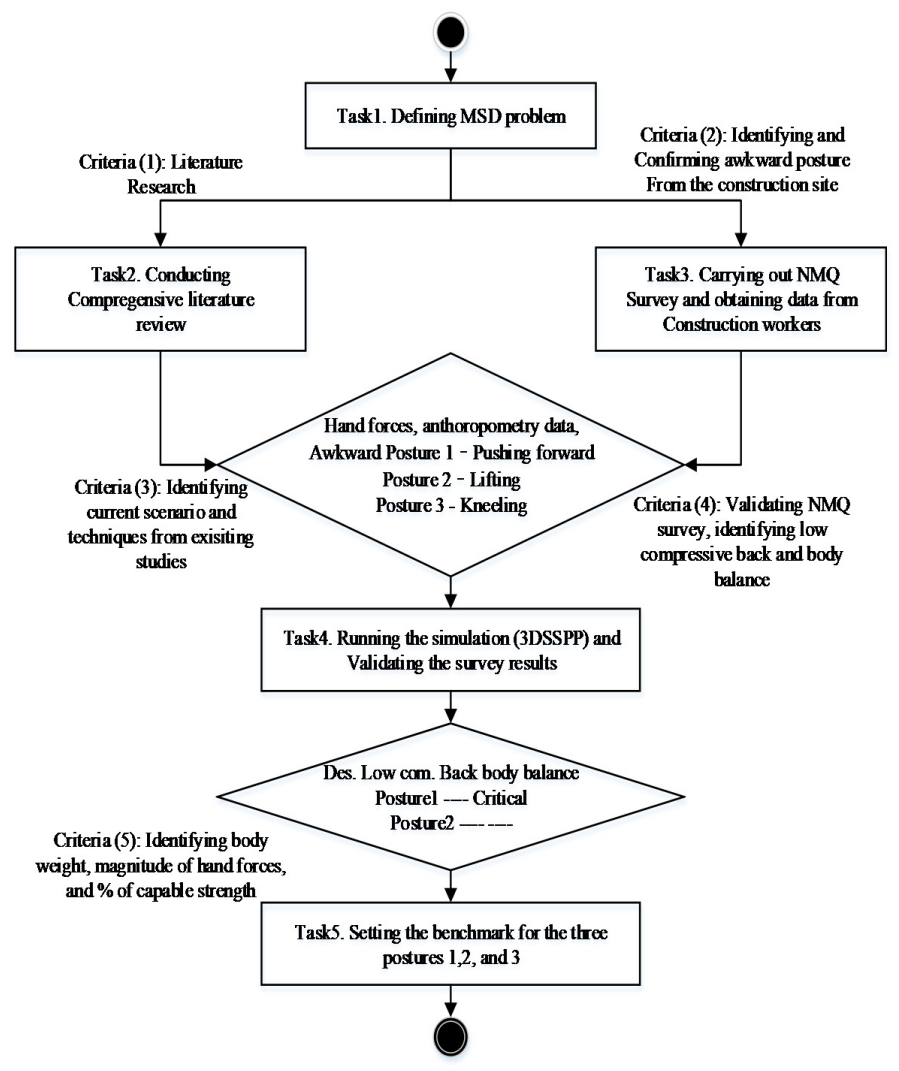

Figure 1. Research method. 


\subsection{Administering the Nordic Musculoskeletal Questionnaire (NMQ)}

The NMQ provides a structured and standardized interview method considering the lower back, neck, and shoulder, studying general complaints from an epidemiological perspective. Its validity and reliability are well accepted in the field of MSD study [16]. The standard questionnaire consists of two parts. One is a general questionnaire of 40 forced-choice items that identify the body parts suffering from musculoskeletal problems; the other is a supplemental questionnaire that considers in depth the problems of the lower back, neck, and shoulder pain [16]. In this study, the NMQ survey was designed and administered to 120 male workers of four high-rise condominium building construction projects in Korea. The participants who were actively engaged in various manual construction operations were identified based on their trade (i.e., carpenters, masons, and ironworkers), task (i.e., ceiling work, material handling, and ground-floor-level helping), and role (i.e., craftsman, journeyman, and helper). The average age of these workers was 48.46 years. Questionnaires were prepared and provided to these workers in envelops. Of the 120 envelops, 28 were returned in either an incomplete or an invalid form. The rate of valid response for the 120 envelopes was $76.66 \%$. In order to obtain accurate data, the objective of the study was clearly explained to the participants before they responded to the survey. After obtaining admissible informed consents from the participants, each criterion, which included a moderate (non-extreme) level of self-reported physical activity, was collected on a daily basis. By adopting the standard NMQ survey process [17], valid anthropometry data along with answers for all questions were obtained. In addition, the extensiveness and precision of the survey were confirmed by the descriptive statistics using the NMQ survey, which included the MSD pain prevalence data for 12 months, frequency of pain over the total working days/weeks, and the distribution of MSD on each body part.

\subsection{Biomechanical Assessment Using Three-Dimensional Static Strength Prediction Program (3D SSPP)}

The biomechanical assessment software 3D SSPP (Version 8.0) was developed at the University of Michigan, USA, and is well accepted as an effective tool for handling the relationship between various lifting motions and lower back pain $[18,19]$. It was used to validate the NMQ survey output analysis in this study. The software identifies not only the physical demand attributed to a task (including posture data, force parameters, and male/female anthropometry), but also predicts the static strength requirements for lifting, pushing, and stooping tasks. It provides the percentage of worker strength performance given a designated task, and the spinal compression forces based on the National Institute of Occupational Safety and Health (NIOSH) guidelines.

\section{Results}

\subsection{Descriptive Analysis of the NMQ Survey Outputs}

Of the 92 participants (87\%) who provided valid questionnaire, responses complained of MSD symptoms attributed to the construction works (Tables 1-3).

Table 1. Height, weight, and body mass index (BMI) of respondents.

\begin{tabular}{cc}
\hline Description & Mean \\
\hline Height (ht.) & $174 \mathrm{~cm}(140-190) \mathrm{cm}$ \\
Weight (wt.) & $75 \mathrm{~kg}(165 \mathrm{lb})$ \\
BMI & $24.8 \mathrm{~kg} / \mathrm{m}^{2}$ \\
\hline
\end{tabular}


Table 2. Tenure and working days.

\begin{tabular}{cc}
\hline Work Experience & Percentages \\
\hline <than equal to 10 years & $54 \%$ \\
$(11-25)$ years & $29 \%$ \\
$>25$ years & $16 \%$ \\
Working Time (Days/Week) & Percentages \\
5 & $19.5 \%$ \\
6 & $64.1 \%$ \\
7 & $16.3 \%$ \\
\hline
\end{tabular}

Table 3. Relation between age groups and MSD pain.

\begin{tabular}{ccccc}
\hline Characteristics & \multirow{2}{*}{ Percentages } & \multicolumn{2}{c}{ Musculoskeletal Disorder } \\
\cline { 4 - 5 } Age (Mean Age:48.46) & & Yes & No \\
\hline $18-30$ & $7 \%$ & $6 \%$ & $1 \%$ \\
\hline $30-35$ & $30 \%$ & $27 \%$ & $3 \%$ \\
\hline $50-65$ & $63 \%$ & $54 \%$ & $9 \%$ \\
\hline Total & $100 \%$ & $87 \%$ & $13 \%$ \\
\hline
\end{tabular}

The age distribution of the respondents was as follows: 7\% were 18 to 30 years old, $30 \%$ were 30 to 50 years old, and $63 \%$ were 50 to 65 years old. The worker's age appeared to be a significant contributor to MSD symptoms. The distribution of workers according to their work experience was as follows: $54 \%$ with less than 10 years' tenure, $29 \%$ with 11 to 25 years' tenure, and $16 \%$ with more than 25 years' tenure. The average body weight and BMI of the population was $75 \mathrm{~kg}$ and 24.8, respectively, which indicates that the construction workers had normal BMI. The longest duration for MSD pain was more than a month for the lower back, followed by the neck and shoulder during the past 12 months (Table 4).

Table 4. Duration of MSD pain in the past 12 months.

\begin{tabular}{cccccc}
\hline Description & Half Day (Nos) & Within 1 Week & Within 1 Month & More than 1 Month & Daily \\
\hline Lower back & 20 & 10 & 10 & 32 & 2 \\
Neck pain & 17 & 25 & 8 & 19 & 2 \\
Shoulder pain & 17 & 9 & 8 & 20 & 1 \\
\hline
\end{tabular}

\subsection{Reconfirming Awkward Postures Contributing to MSDs}

Existing research portends that pushing, lifting, and kneeling are major awkward postures contributing to MSDs. The NMQ questionnaire survey found that nearly $43 \%, 38 \%, 16 \%$, and $16 \%$ of the studied population suffered from pain in the shoulder, lower back, neck, and knee, respectively (Table 5). The main awkward postures (e.g., lifting, pulling, kneeling posture) obtained by these surveys on construction workers' muscle pain were chosen for biomechanical simulation to validate the survey results. Since the amount of pain for upper back, hip, and wrist were nominal, these postures were not included in the simulation. In addition, the main motions contributing to each MSD were identified. Shoulder pain was the outstanding MSD complaint during daily working hours. It was mainly attributed to the bending and/or twisting of the body. Working in a bent or twisted body posture for long hours daily may increase this MSD symptom significantly. It was found that leg squatting while performing tasks on the ground or floor was an awkward motion that involved the knee acutely. In addition, the most common awkward postures at construction job sites were pushing forward (posture 1), lifting (posture 2), and kneeling (posture 3). 
Table 5. MSD profile among respondents.

\begin{tabular}{cccc}
\hline MSDs & Number & Percentage (\%) & Motions \\
\hline Neck pain & 15 & 16 & Groundwork \\
Shoulder pain & 40 & 43 & Lifting, pushing, pulling \\
Arm pain & 15 & 16 & Pushing \\
Wrist pain & 13 & 14 & Pulling \\
Upper back pain & 5 & 5 & Push/pull \\
Lower back pain & 35 & 38 & Lifting, pushing, pulling \\
Hip pain & 4 & 4 & - \\
Knee pain & 15 & 16 & Kneeling \\
Ankle/foot pain & 10 & 11 & - \\
\hline
\end{tabular}

\subsection{Simulation Modeling and Analysis Using 3DSSPP}

Anthropometry data were obtained from the survey at the aforementioned four Korean construction sites and provided the posture details and input parameters for workers (including average height $(174 \mathrm{~cm})$, weight $(165 \mathrm{lb})$, and left- and right-hand forces). These data are listed in Table 6 . They were used as input data for the simulation model.

Table 6. Anthropometry data of each posture.

\begin{tabular}{|c|c|c|c|c|c|}
\hline \multirow{2}{*}{ Posture Detail } & \multirow{2}{*}{ Gender } & \multirow{2}{*}{ Average Height (cm) } & \multirow{2}{*}{ Average Weight (lb) } & \multicolumn{2}{|c|}{ Hand Forces } \\
\hline & & & & Left (lb) & Right (lb) \\
\hline Pushing forward & Male & 174 & 165 & 20 & 20 \\
\hline Lifting & Male & 174 & 165 & 25 & 25 \\
\hline Kneeling & Male & 174 & 165 & 10 & 10 \\
\hline
\end{tabular}

\subsubsection{Analyzing Motion of Pushing Forward}

The pushing forward motion shown in Figure 2a did not cause a severe risk of injury to the lower back because it demanded a low lumbar disc compression force (L4/L5) that was less than the NIOSH back compression action limit of $770 \mathrm{lb}(3400 \mathrm{~N})$. The compression force on a disc of the spine was recommended by the NIOSH. The safety level for disc compression force during lifting objects in manual material handling should be less than $3400 \mathrm{~N}$ (Waters et al. 1993). While pushing forward against a force of $295 \mathrm{lb}(1338 \mathrm{~N})$, the worker did not bend his torso. Therefore, high flexion of the back was not needed to move forward an object of weight up to $9 \mathrm{~kg}(20 \mathrm{lb})$ in the simulation experiment, as shown in Figure $2 b$. The heavier the object that the worker pushes and/or the greater bender the extent to which the worker bends his/her torso, the higher the compression force. The simulation output analysis confirmed that only $35 \%$ and $62 \%$ of the surveyed workers could perform the posture of the wrist joint and that of the knee joint, respectively, and manifested in the pushing forward motion. Further, the other joints fell within the critical zone, indicating the influence of the pushing forward motion on body balance (see Table 7).

Table 7. Simulation output analysis of pushing forward.

\begin{tabular}{ccccccccccc}
\hline S.N. & $\begin{array}{c}\text { Posture } \\
\text { Type }\end{array}$ & Description & $\begin{array}{c}\text { Body } \\
\text { Weight }\end{array}$ & $\begin{array}{c}\text { Hand } \\
\text { Forces (H.F.) }\end{array}$ & Knee & Shoulder & Hip & Wrist & $\begin{array}{c}\text { Body } \\
\text { Balance }\end{array}$ & $\begin{array}{c}\text { Low Back } \\
\text { Compression }\end{array}$ \\
\hline 1 & $\begin{array}{c}\text { Pushing } \\
\text { forward }\end{array}$ & $\begin{array}{c}\text { Pushing } 20 \\
\text { lb load }\end{array}$ & $75 \mathrm{~kg}$ & $20 \mathrm{lb}$ & $62 \%$ & $99 \%$ & $98 \%$ & $35 \%$ & Critical & $295 \mathrm{lb}(<770 \mathrm{lb})$ \\
\hline
\end{tabular}




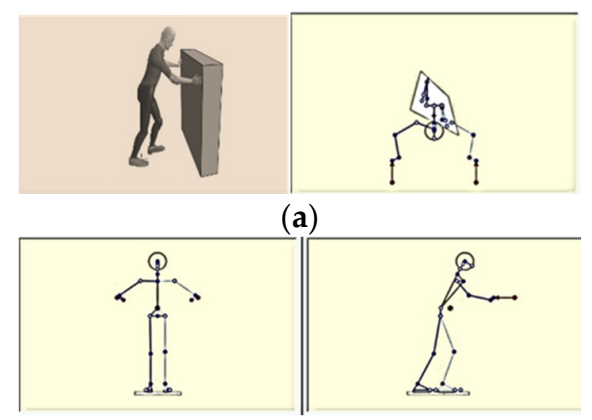

(b)

Figure 2. Pushing forward motion (a), and limb angles in pushing forward motion (b) obtained by the three-dimensional static strength prediction program (3D SSPP).

The change in location of the center of gravity of the worker's body dictated the functional stability region obtained while releasing the pushing forward posture and was projected on the body balance graph by obtaining 30 window frames within a second, as shown in Figure 3. The virtual manikin retained static balance when the value of hand forces was decreased. The manikin could bend further forward if its center of gravity was located further backward from its base support. Thus, it may be beneficial either to hire a stronger worker or to decrease the hand force according to the BMI of the workers in order to avoid falling accidents.

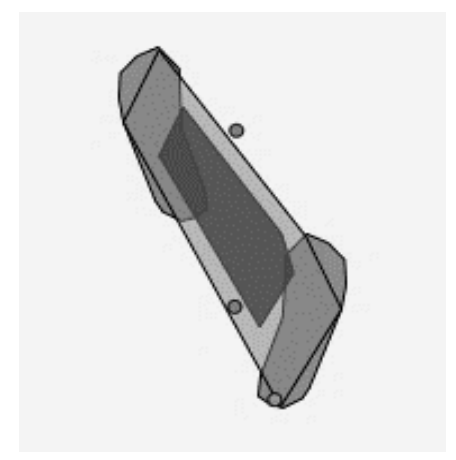

Figure 3. Center of gravity of body in pushing forward motion.

\subsubsection{Analyzing Lifting Motion}

Four different postures of lifting a $25 \mathrm{lb}$ box may cause a severe injury to the low back and were thus modeled in Figure 4a-d. The compression force (L4/L5), i.e., $3821 \mathrm{~N}$ (859 lb), exceeded the NIOSH back compression action limit of $3400 \mathrm{~N}$. Since the worker bent his torso, these postures required high flexion to move an object ( $25 \mathrm{lb}$ weight in the simulation experiment) forward. It was confirmed that the other joints fall within the critical yellow zone.

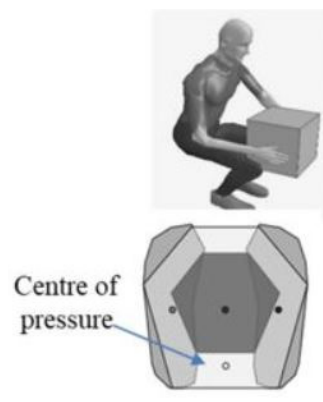

(a)

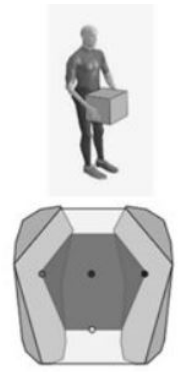

(b)

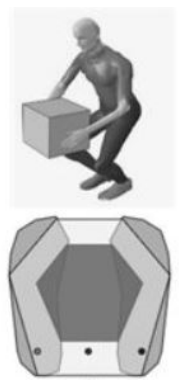

(c)

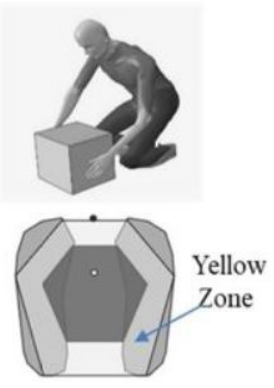

(d)

Figure 4. Body balance in lifting postures based on center-of-pressure (COP)—acceptable (a), acceptable (b), critical (c), and unacceptable (d). 
These postures may cause severe low back injuries since the compression force (L4/L5) exceeds the NIOSH back compression action limit of $3400 \mathrm{~N}$ (Table 8).

Table 8. Simulation output analysis of lifting.

\begin{tabular}{|c|c|c|c|c|c|c|c|c|c|c|}
\hline S.N. & $\begin{array}{c}\text { Posture } \\
\text { Type }\end{array}$ & Description & $\begin{array}{c}\text { Body } \\
\text { Weight }\end{array}$ & $\begin{array}{c}\text { Hand } \\
\text { Forces (H.F.) }\end{array}$ & Knee & Shoulder & Hip & Wrist & $\begin{array}{c}\text { Body } \\
\text { Balance }\end{array}$ & $\begin{array}{c}\text { Low Back } \\
\text { Compression }\end{array}$ \\
\hline 1 & & Carrying $25 \mathrm{lb}$ box & $75 \mathrm{~kg}$ & $25 \mathrm{lb}$ & $87 \%$ & $88 \%$ & $92 \%$ & $77 \%$ & A & $824 \mathrm{lb}(>770 \mathrm{lb})$ \\
\hline 2 & & $\begin{array}{l}\text { Standing and } \\
\text { carrying } 25 \mathrm{lb} \text { box }\end{array}$ & $75 \mathrm{~kg}$ & $25 \mathrm{lb}$ & $100 \%$ & $70 \%$ & $82 \%$ & $80 \%$ & A & $859 \mathrm{lb}(>770 \mathrm{lb})$ \\
\hline 3 & & $\begin{array}{l}\text { Going to put the } \\
25 \mathrm{lb} \text { box on } \\
\text { the floor }\end{array}$ & $75 \mathrm{~kg}$ & $25 \mathrm{lb}$ & $100 \%$ & $87 \%$ & $99 \%$ & $85 \%$ & C & $343 \mathrm{lb}(<770 \mathrm{lb})$ \\
\hline 4 & & $\begin{array}{l}\text { Put the } 25 \mathrm{lb} \text { box } \\
\text { onto the floor }\end{array}$ & $75 \mathrm{~kg}$ & $25 \mathrm{lb}$ & $98 \%$ & $94 \%$ & $90 \%$ & $78 \%$ & U & $723 \mathrm{lb}(<770 \mathrm{lb})$ \\
\hline
\end{tabular}

Note: $\mathrm{A}=$ acceptable, $\mathrm{C}=$ critical, $\mathrm{U}=$ unacceptable.

The maximum and the minimum compressive forces exerted while performing the lifting motion were $859 \mathrm{lb}(3821 \mathrm{~N})$ and $343 \mathrm{lb}(1525 \mathrm{~N})$, respectively. Since the worker did not bend his/her torso, these postures did not require high flexion to move forward an object weighing $12 \mathrm{~kg}(25 \mathrm{lb})$ used in the simulation experiment. The compression force increased if the worker bent his/her torso to push a heavier object. Only $77 \%, 87 \%$, and $70 \%$ of the population could perform the corresponding postures of the wrist, knee, and shoulder joints, respectively. A posture may have static balance, fall within the yellow zone, or tend to cause a fall. The change in the location of the center of gravity while releasing the lifting posture was projected on the body balance graph, as shown in Figure 5. Body balance was categorized as acceptable, critical, or unacceptable by 3D SSPP when the COP was within, on the boundary, or outside the functional stability region, respectively, as depicted in Figure $4 \mathrm{a}-\mathrm{d}$. The virtual manikin retained static balance when the value of hand force was decreased from $25 \mathrm{lb}$ to $15 \mathrm{lb}$ The further backward the center of gravity of the manikin was located from its base support, the farther the manikin bent. Thus, it is beneficial to either hire a stronger worker or decrease the hand force according to the worker's BMI to avoid a dropping accident.

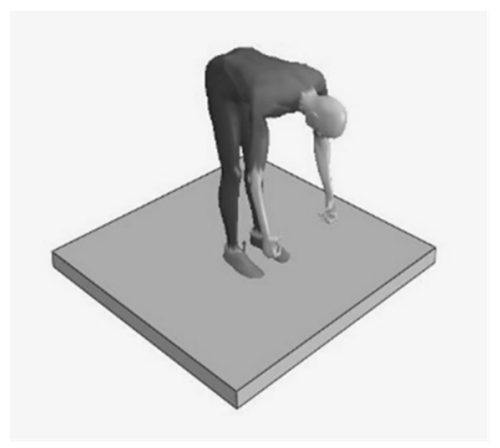

(a)

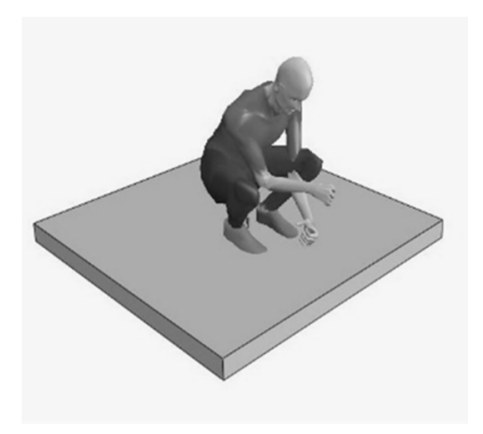

(b)

Figure 5. Reinforcing postures for (a) $25 \mathrm{fps}$ and (b) $20 \mathrm{fps}$. 


\subsubsection{Analyzing Kneeling Posture}

Two different postures reinforcing rebar for 25 frames per second and 20 frames per second were modeled, as shown in Figure 5a,b, respectively. The compression force (L4/L5), i.e., $742.6 \mathrm{lb}$ (3303 N), was within the NIOSH back compression action limit of $3400 \mathrm{~N}$ (see Table 9), resulting in a margin of a lower back injury. Since the worker must bend his torso, these postures require high flexion to move an object weighing $9 \mathrm{~kg}(20 \mathrm{lb}$ ) forward in the simulation experiment. Only $74 \%$, $72 \%$, and $84 \%$ of the population could perform the holding posture of the knee, ankle, and torso joints, respectively. Further, only $70 \%$ and $52 \%$ of the population could perform the reinforcing posture of the wrist and knee joints, respectively. It was confirmed that the other joints engaged in the holding posture were unacceptable, but those engaged in the reinforcing posture were acceptable.

Table 9. Simulation output analysis of kneeling.

\begin{tabular}{|c|c|c|c|c|c|c|c|c|c|c|}
\hline S.N. & $\begin{array}{l}\text { Posture } \\
\text { Type }\end{array}$ & Description & $\begin{array}{c}\text { Body } \\
\text { Weight }\end{array}$ & $\begin{array}{c}\text { Hand } \\
\text { Forces (H.F.) }\end{array}$ & Knee & Shoulder & Hip & Wrist & $\begin{array}{c}\text { Body } \\
\text { Balance }\end{array}$ & $\begin{array}{c}\text { Low Back } \\
\text { Compression }\end{array}$ \\
\hline 1 & & $\begin{array}{l}\text { Holding position } \\
\text { (before kneeling } \\
\text { position) }\end{array}$ & $75 \mathrm{~kg}$ & $10 \mathrm{lb}$ & $74 \%$ & $100 \%$ & $81 \%$ & $99 \%$ & $\mathrm{U}$ & $742.6 \mathrm{lb}(<770 \mathrm{lb})$ \\
\hline 2 & & $\begin{array}{c}\text { Reinforcing } \\
\text { position }\end{array}$ & $75 \mathrm{~kg}$ & $10 \mathrm{lb}$ & $100 \%$ & $70 \%$ & $82 \%$ & $80 \%$ & A & $56.9 \mathrm{lb}(<770 \mathrm{lb})$ \\
\hline
\end{tabular}

Note: $\mathrm{U}=$ unacceptable, $\mathrm{A}=$ acceptable.

Two different postures involving stooping (bending at the waist) with a hand tool for 25 frames per second and squatting down to reinforce rebars for 20 frames per second were modeled, as shown in Figure $6 \mathrm{a}, \mathrm{b}$. The center of gravity of the body while performing these postures was located away from the support, leading to a tendency to fall. The center of gravity of the virtual manikin remained in the base and the manikin maintained static balance. Indeed, either decreasing the hand force or maintain a constant hand force will be a good preventive measure to avoid a falling accident for a given BMI.

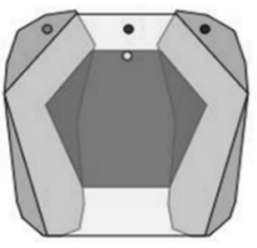

(a)

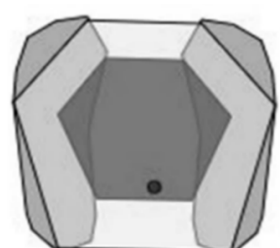

(b)

Figure 6. Stooping postures with hand tool for (a) $25 \mathrm{fps}$ and (b) reinforcing rebar for $20 \mathrm{fps}$.

\subsection{Tradeoff between BMI and Magnitude of Force}

While decreasing hand force when pushing forward, lifting, and kneeling, the low back compression, body balance, and the percentage of strength capability were obtained. These values are listed in Table 10. The body balance in the lifting posture was critically unacceptable, but it became stable as the hand force decreases. The lower back compression decreased from $942 \mathrm{lb}$ to $752 \mathrm{lb}$, which was less than the standard level $(770 \mathrm{lb})$, as the hand force decreased. The percentage of strength capability increased remarkably to more than $90 \%$ for all the body joints, including the knee, shoulder, wrist, and hip, as seen from the data in Table 10. The benchmark provided admissible evidence that a Korean worker with an average weight of $75 \mathrm{~kg}$ can carry $16 \mathrm{lb}, 19 \mathrm{lb}$, and $16 \mathrm{lb}$ of loads when performing tasks involving pushing forward, lifting, and kneeling, respectively. When the hand force was greater than these loads applied to the manikin (i.e., the virtual worker) weighing $75 \mathrm{~kg}$, the body tended to be unbalanced in those postures. 
Table 10. Tradeoff between BMI and the magnitude of forces in different postures.

\begin{tabular}{|c|c|c|c|c|c|c|c|c|c|c|}
\hline S.N. & Posture Type & Description & $\begin{array}{c}\text { Body } \\
\text { Weight }\end{array}$ & $\begin{array}{c}\text { Hand } \\
\text { Forces (H.F.) }\end{array}$ & Knee & Shoulder & Hip & Wrist & $\begin{array}{c}\text { Body } \\
\text { Balance }\end{array}$ & $\begin{array}{c}\text { Low Back } \\
\text { Compression }\end{array}$ \\
\hline \multirow[b]{2}{*}{1} & $\begin{array}{l}\text { Pushing } \\
\text { forward }\end{array}$ & P-1 & $75 \mathrm{~kg}$ & $20 \mathrm{lb}$ & $62 \%$ & $99 \%$ & $98 \%$ & $35 \%$ & C & $295 \mathrm{lb}$ \\
\hline & $\begin{array}{l}\text { Pushing } \\
\text { forward (after } \\
\text { reducing H.F.) }\end{array}$ & P-1 & $75 \mathrm{~kg}$ & $16 \mathrm{lb}$ & $98 \%$ & $99 \%$ & $96 \%$ & $63 \%$ & A & $309 \mathrm{lb}$ \\
\hline \multirow[b]{2}{*}{2} & Lifting & P-2 & $75 \mathrm{~kg}$ & $25 \mathrm{lb}$ & $99 \%$ & $96 \%$ & $86 \%$ & $91 \%$ & $C$ and $\mathrm{U}$ & $942 \mathrm{lb}$ \\
\hline & $\begin{array}{l}\text { Lifting (after } \\
\text { reducing H.F.) }\end{array}$ & P-2 & $75 \mathrm{~kg}$ & $19 \mathrm{lb}$ & $99 \%$ & $90 \%$ & $88 \%$ & $91 \%$ & A & $752 \mathrm{lb}$ \\
\hline \multirow[b]{2}{*}{3} & Kneeling & P-3 & $75 \mathrm{~kg}$ & $20 \mathrm{lb}$ & $74 \%$ & $100 \%$ & $81 \%$ & $98 \%$ & $\mathrm{U}$ & $742.6 \mathrm{lb}$ \\
\hline & $\begin{array}{l}\text { Kneeling (after } \\
\text { reducing H.F.) }\end{array}$ & P-3 & $75 \mathrm{~kg}$ & $16 \mathrm{lb}$ & $90 \%$ & $100 \%$ & $96 \%$ & $99 \%$ & A & $700 \mathrm{lb}$ \\
\hline
\end{tabular}

Note: $\mathrm{P}-1=$ posture $1, \mathrm{P}-2=$ posture $2, \mathrm{P}-3=$ posture $3, \mathrm{C}=$ critical, $\mathrm{A}=$ acceptable, $\mathrm{U}=$ unacceptable.

\section{Discussion}

The method combining the NMQ survey, biomechanical analysis, and benchmark approach facilitates quantitative MSD control over the muscle stress of construction workers. It encourages informed decision making on recruiting appropriate workers considering their physical merits (i.e., muscle strength) for a specific job function in a construction operation. It fills gaps the computational method handling different parts MSD that the existing methods had not adequately described to access the health risks of construction workers by doing simulation on construction worker postures. It may replicate specific task, finding construction workers' MSD issues attributed to using semi-automatic or fully automatic tools. The biomechanical analysis outputs involved in the unacceptable and awkward postures (Tables 5-7) that impose high risk provide a tool to field employment managers to identify the tradeoff between BMI and the magnitude of the hand forces to execute preventive measures (i.e., exercise programs and engineering controls) [20]. Few studies provide an insight into reducing work-related musculoskeletal injuries given the existing preventive measures. This lack of research may be attributed to the fact that analysis of work tasks at a job site is a complex task because of various factors (e.g., organizational, human, task factors). The new hybrid method allows an elaborate analysis of work postures associated with construction tasks by considering job-specific risks attributed to process, motion, and posture. Note that the method identifies potential MSDs associated with the awkward postures of a worker performing a job function while controlling other job-site variables.

The limitations of the method are related to the biomechanical issues as follows: First, it is desirable that sophisticated postures are considered jointly by accommodating 3D motion analysis in a future version of the method. A worker's muscle strength may not be determined by the biomechanical simulation model alone. However, the model may provide a control tool for MSD safety and health of workers by validating the physical demands (e.g., lower back compressive strength, percentage of strength capability, and body balance) obtained by expert group surveys of the construction community. Second, the momentary and transitory issues involved in motions have been intensified among the workers involved in construction. A controlled experiment on construction workers is not feasible because it is not easy to have many workers perform identical motions at a construction job site. In addition, their motions are momentary, transitory, and involve multiple tasks at a time. It will be commendable to perform controlled experiments in a simulated construction job site to generalize the outputs obtained by the method. Third, it will be beneficial to track each motion activated by a participant performing a specific task. It may encourage the elaborative evaluation of MSD. For instance, biomechanical human simulation may effectively predict the relation between muscle strength for a construction task and the workplace dimension by using identified awkward postures. Fourth, extensive controlled experiments with different exercise protocols (i.e., the type of working layouts, frequency of postures, intensity of motion, and duration of posture) may contribute to identifying unknown variables that influence the relationship between two variables and to secure the validity of the method and its corresponding data. 


\section{Conclusions}

The main contribution of this study is that the hybrid method lends itself to scientific fact-finding. A set of benchmarks was established using the model by manipulating the BMI and hand forces of the workers. The method provides a means to not only understand the contemporary scenario of MSD in construction workers but also to establish a practical benchmark based on the physical capability of workers that is helpful to construction managers during recruitment. It confirms that $87 \%$ of respondents suffering from MSD had three common awkward postures. Further, the simulation output analysis provided admissible evidence that the muscle stress involved in lower back compression exceeds the tolerance. The body of a worker suffering from back pain may be unstable while performing a work task. The awkward postures in which the body balance is proportional to the loads aggravate the situation. Indeed, decreasing the hand forces makes the posture static, thereby reducing the MSD. It will be beneficial to incorporate these findings into computer-based predictions to secure the effectiveness and validity of biomechanical human simulations. The current version of the developed method handles static postures, not dynamic movements. It is desirable to extend the new method to assess real-time work processes to identify the dynamics in real practices in the future study. The new method promotes academic division in the multi-paradigm computing approach and may contribute to the advancement of the construction workers' health assessment when monitoring the next generation.

Author Contributions: Conceptualization, S.P. and D.-E.L.; Data curation, M.Y. and B.Y.C.; Formal analysis, S.P., M.Y., B.Y.C. and D.-E.L.; Funding acquisition, D.-E.L.; Investigation, S.P. and M.Y.; Methodology, S.P.; Project administration, D.-E.L.; Resources, S.P.; Software, S.P. and B.Y.C.; Supervision, D.-E.L.; Validation, D.-E.L.; Visualization, S.P. and B.Y.C. Writing—original draft, S.P.; Writing—review \& editing, D.-E.L. All authors have read and agreed to the published version of the manuscript.

Funding: This work was supported by the National Research Foundation of Korea (NRF) grant funded by the Korea government (MSIT) (NRF-2018R1A5A1025137) and (NRF-2019R1I1A1A01062006).

Conflicts of Interest: The authors declare no conflict of interest.

\section{References}

1. OSHA. Ergonomics: Prevention of Musculoskeletal Disorders in the Workplace. Available online: https: //www.osha.gov/SLTC/ergonomics/index.html (accessed on 13 July 2020).

2. Choi, S.D.; Yuan, L.; Borchardt, J.G. Critical Analyses of Work-related Musculoskeletal Disorders and Practical Solutions in Construction. Proc. Hum. Factors Ergon. Soc. Annu. Meet. 2014, 58, 1633-1637. [CrossRef]

3. Park, J.; Kim, S.G.; Park, J.-S.; Han, B.; Kim, K.B.; Kim, Y. Hazards and health problems in occupations dominated by aged workers in South Korea. Ann. Occup. Environ. Med. 2017, 29, 27. [CrossRef] [PubMed]

4. Salas, E.A.; Vi, P.; Reider, V.L.; Moore, A.E. Factors affecting the risk of developing lower back musculoskeletal disorders (MSDs) in experienced and inexperienced rodworkers. Appl. Ergon. 2016, 52, 62-68. [CrossRef]

5. Chen, J.; Qiu, J.; Ahn, C. Construction worker's awkward posture recognition through supervised motion tensor decomposition. Autom. Constr. 2017, 77, 67-81. [CrossRef]

6. Kim, H.; Choi, J. The relation between obesity and cancer of gastrointestinal tract in Korea: The data from Statistic Korea between 2001 and 2016. Ann. Oncol. 2019, 30, ix55. [CrossRef]

7. Golabchi, A.; Han, S.; Seo, J.; Han, S.; Lee, S.; Al-Hussein, M. An Automated Biomechanical Simulation Approach to Ergonomic Job Analysis for Workplace Design. J. Constr. Eng. Manag. 2015, 141, 04015020. [CrossRef]

8. Lee, W.; Seto, E.; Lin, K.-Y.; Migliaccio, G. An evaluation of wearable sensors and their placements for analyzing construction worker's trunk posture in laboratory conditions. Appl. Ergon. 2017, 65, 424-436. [CrossRef] [PubMed]

9. Alwasel, A.; Elrayes, K.; Abdel-Rahman, E.M.; Haas, C. Sensing Construction Work-Related Musculoskeletal Disorders (WMSDs). In Proceedings of the 28th International Symposium on Automation and Robotics in Construction (ISARC 2011), Seoul, Korea, 29 June-2 July 2011; International Association for Automation and Robotics in Construction (IAARC): Seoul, Korea, 2011; pp. 164-169. 
10. Chang, J.D.; Bennis, F.; Ma, L. Muscle Fatigue Analysis Using OpenSim. In Digital Human Modeling. Applications in Health, Safety, Ergonomics, and Risk Management: Ergonomics and Design; Proceedings of the International Conference on Digital Human Modeling, Vancouver, BC, Canada, 9-14 July 2017; Duffy, V., Ed.; Springer International Publishing: Cham, Switzerland, 2017; Volume 10286, pp. 95-106.

11. Valero, E.; Sivanathan, A.; Bosché, F.; Abdel-Wahab, M. Musculoskeletal disorders in construction: A review and a novel system for activity tracking with body area network. Appl. Ergon. 2016, 54, 120-130. [CrossRef] [PubMed]

12. Kong, L.; Li, H.; Yu, Y.; Luo, H.; Skitmore, M. Quantifying the physical intensity of construction workers, a mechanical energy approach. Adv. Eng. Inform. 2018, 38, 404-419. [CrossRef]

13. Wells, R. Why have we not solved the MSD problem? Work 2009, 34, 117-121. [CrossRef] [PubMed]

14. Choi, S.D. Investigation of Ergonomic Issues in the Wisconsin Construction Industry. 2016. Available online: https://www.researchgate.net/publication/252554958 (accessed on 14 July 2020).

15. Burgess-Limerick, R. Participatory ergonomics: Evidence and implementation lessons. Appl. Ergon. 2017, 68, 289-293. [CrossRef] [PubMed]

16. Kuorinka, I.; Jönsson, B.; Kilbom, A.; Vinterberg, H.; Biering-Sorensen, F.; Andersson, G.; Jørgensen, K. Standardised Nordic questionnaires for the analysis of musculoskeletal symptoms. Appl. Ergon. 1987, 18, 233-237. [CrossRef]

17. Dickinson, C.; Campion, K.; Foster, A.; Newman, S.; O’Rourke, A.; Thomas, P. Questionnaire development: An examination of the Nordic Musculoskeletal questionnaire. Appl. Ergon. 1992, 23, 197-201. [CrossRef]

18. Chaffin, D.B. Development of computerized human static strength simulation model for job design. Hum. Factors Ergon. Manuf. 1997, 7, 305-322. [CrossRef]

19. University of Michigan. Centre for Ergonomics: 3D Static Strength Prediction Program Version 7.0.4. 2017. Available online: https://c4e.engin.umich.edu/tools-services/3dsspp-software/ (accessed on 7 March 2017).

20. Holmström, E.; Ahlborg, B. Morning warming-up exercise-Effects on musculoskeletal fitness in construction workers. Appl. Ergon. 2005, 36, 513-519. [CrossRef] [PubMed]

(C) 2020 by the authors. Licensee MDPI, Basel, Switzerland. This article is an open access article distributed under the terms and conditions of the Creative Commons Attribution (CC BY) license (http://creativecommons.org/licenses/by/4.0/). 